\title{
Construction of Micro Mobile Course Based on WeChat Platform
}

\author{
Zhuang Miao, Yang Li, Wei-guang Xu, Jia-bao Wang, \\ $\mathrm{Ge} \mathrm{Li}$ \\ College of Command Information Systems \\ Army Engineering University \\ Nanjing, China
}

\author{
Zhi-jie Zhao \\ No. 31700 Unit of PLA \\ Liaoyang, China
}

\begin{abstract}
At present, WeChat's effect has gone beyond the original instant messaging services. WeChat platform combines micro courses with mobile terminals perfectly. It enables students to learn anytime and anywhere and is a new teaching mode. In this paper, the feasibility of establishing the course of micro mobile platform based on WeChat is analyzed. The principles of micro mobile curriculum construction are presented. The teaching mode of micro mobile course is designed. The interaction mechanism of blended learning based on WeChat platform is discussed. Finally, the construction method of mobile micro course based on the WeChat platform is put forward. The works of this paper are helpful to the study of new teaching mode in new era.
\end{abstract}

Keywords-WeChat platform; Micro mobile course; Teaching mode; Interaction mechanism

\section{INTRODUCTION}

Recently, with the development of the information technologies, college students are willing to accept the convenient and interesting way of learning. More and more people take use of fragmented time through the mobile terminal to access and release micro messages, communicate and interact. WeChat combines micro courses and mobile terminals perfectly. People learn anytime and anywhere, which has become a new teaching mode.

Applying WeChat platform in micro mobile learning has three advantages: convenience of implementation, efficiency of communication and integration of resources. The design and application of micro mobile courses based on mobile terminal is an inevitable trend in the new era. In this paper, the concept of micro mobility for informal learning is put forward, in which WeChat public platform is taken as a learning platform. And then the design mode of micro mobile course is discussed, which is helpful to explore new teaching mode. Teaching based on micro mobile course is a kind of mobile learning and refers to its design model.

\section{RELATED WORKS}

Some research works focus on the teaching theory, mode, design and implementation. Siemens considered that behaviorism, cognitivism, and constructivism are the three broad learning theories most often utilized in the creation of instructional environments and these theories were developed in a time when learning was not impacted [1]. Dillard explored the need of designing effective and efficient mobile learning for adult learners and presented six key principles for use by instructional designers including the need to design: a simple and intuitive interface, interactive multi-media, short and modular lessons, engaging and entertaining activities, contextually relevant and meaningful content, and just-in-time delivery [2]. Elias extended a previous analysis of universal instructional design principles in distance education by applying them to the design of mobile learning. Eight principles with particular relevance for distance education were selected, and their recommendations are discussed in relation to the design of educational materials for a range of mobile devices [3]. Tsai developed a course development model for the mobile learning context and proposed six stages of the mobile learning curriculum model [4]. Zhan discussed the inevitability of open micro-mobile education, analyzed the present situation of open micro-mobile education from aspects of education system and course resources construction and put forward three suggestions for open micro-mobile education [5].

Sun introduced a cloud-based system, which can organize learners into a better teamwork context and customize micro learning resources in order to meet personal demands in real time. Particularly, a smart micro learning environment can be built by a newly designed SaaS, in which educational data mining techniques are mainly employed to understand learners' behaviors and recognize learning [6]. Ma built a WeChat based mode to assist college English teaching by using a method of questionnaires and in-depth interviews to conduct an empirical study of this model. Then he proposed that WeChat public platform can aid college English teaching [7]. Song designed a mobile learning platform and implemented based on We Chat and micro-site. The learning platform provided a convenient mobile learning platform for students in higher vocational colleges and students can make use of the fragmentation of time anywhere, autonomous search and choose the courses of interest to learn [8]. 


\section{THEORETICAL FOUNDATION OF MICRO MOBILE COURSE TEACHING}

\section{A. Constructivist theory}

Compared with objectivism, constructivism no longer emphasizes the existence of independent knowledge. A teacher is not a mere intellectual presenter. On the basis of students' understanding, they are guided to construct meaningful knowledge to produce new interpretations. Students understand and interpret new knowledge on the basis of their own previous experience, thus becoming active builders. Different learners have different understanding of the same problem, which makes learners become valuable learning resources for other learners. Knowledge is acquired by means of meaning construction under the help of teachers and other learners in a certain situation. It is not acquired through the direct teaching of the teacher.

\section{B. Situated cognition and learning theory}

Situated cognition and learning theory hold that context is the basis of all cognitive activities. The theory holds that human actions come from direct contact and interaction with the environment. Situated learning takes social interaction as an important component of situated learning. Situation based learners are not passive observers, but formal participants in the community. Participants construct their own knowledge in real situations by interacting with expert peers. In the community, participants share resources and their understanding of the same problem.

\section{Humanism thought}

Learning can be divided into two types: cognitive learning and experiential learning, or meaningless learning and meaningful learning. Experiential learning focuses on the accumulation of learners' experience, and takes the students' spontaneity and initiative as the motivation of learning. It combines learning with learners' desires, interests and needs. Therefore, experiential learning can promote the development of individual learners. Humanism advocates learners to study freely. The task of teachers is not to teach learners to learn knowledge and how to learn, but to believe in the potential of learners. Create good situations for learners and provide a variety of learning resources to enable them to learn how to learn.

As a new platform, WeChat can help learners to seek support and help according to their own experience and learning needs. WeChat can enable them to gain different understanding of knowledge in the process of obtaining help and support, so as to actively recombine and integrate their own knowledge structure. In the process of learning by using WeChat, learners can participate in learning in a small learning community. In the process of good interaction, the relationship between learners will continue to be strengthened, their interaction will be further strengthened, their ability will continue to improve, and this increase will promote the meaning of knowledge construction.

\section{Teaching Design of Micro MobiLe course}

\section{A. Construction Principles of Micro Mobile Course}

Purpose. The use of WeChat should be linked with classroom teaching and serve the teaching objectives. The contents of the study and discussion should be carried out around the teaching objectives.

Combining Teachers and Students. In the process of learning for both teachers and students should be given full attention, it is necessary to recognize the role of teachers in imparting knowledge, teaching organization, have enthusiasm fully affirmed the dominant position of students to mobilize the students.

Optimal Combining Factors. According to the characteristics of students and teaching content, choice of teaching content presentation, teaching content, teaching strategies, teaching media and other forms of organization, in the specific implementation process, should consider the best combination.

\section{B. Teaching Mode of Micro Mobile Course}

WeChat can be regarded as a kind of teaching platform based on blended learning mode and it emphasizes both learning and teaching. Hybrid learning is on the basis of traditional teaching design and follow the general process of instructional design. Hybrid learning has the mobile terminal' $s$ advantage in informal environment and can enhance students' mobile learning effect. The teaching design process is shown in Figure 1.

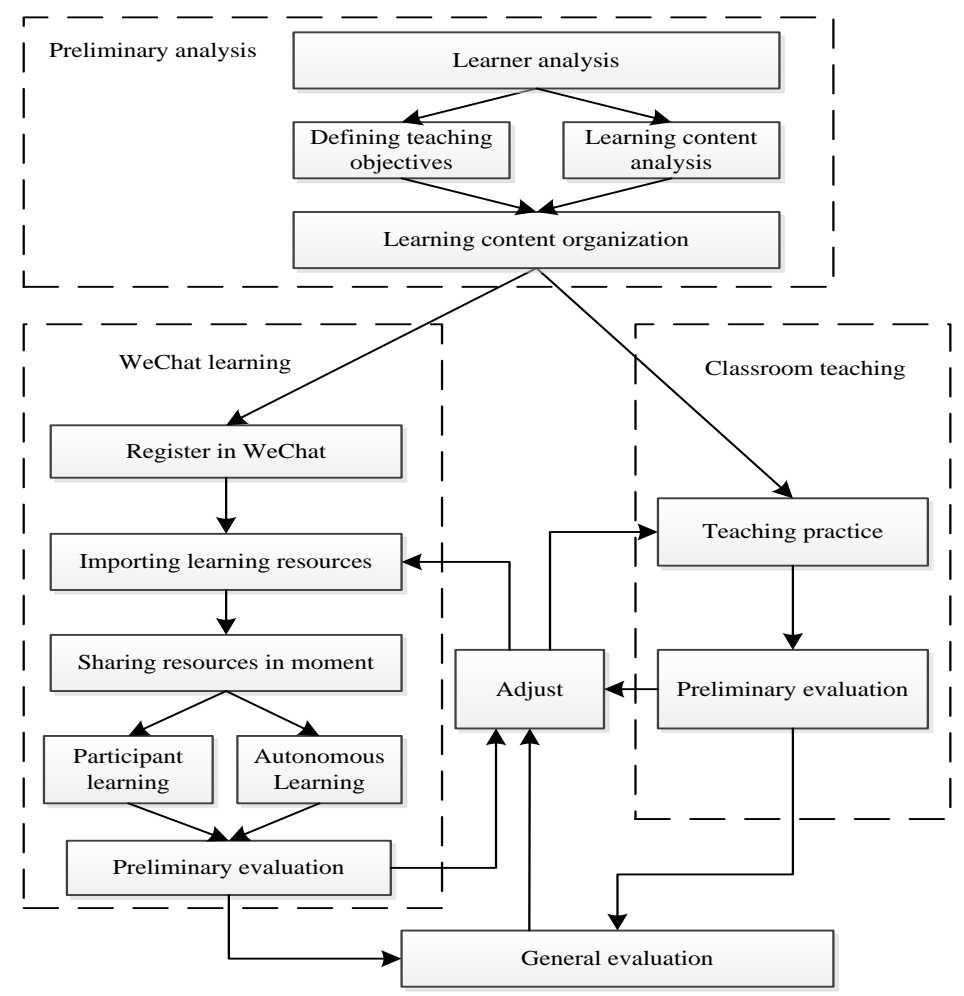

Fig. 1. Teaching design based on WeChat platform 
The general process of teaching model mainly includes learning content analysis, determination of teaching objectives, combination of classroom teaching and WeChat learning, blended learning, summary and evaluation. Different teaching systems need different design process patterns, and there are different design process patterns under different teaching conditions.

After preliminary analysis, to determine the starting point of teachers teaching, and then to WeChat as a platform, the implementation of blended learning in the whole process, teachers should play a leading role to develop hybrid learning strategy, control of the hybrid learning process. According to the relevant content of the classroom teaching, formulate suitable for WeChat learning knowledge point, learning theme, and use WeChat group function to release to students. The learning contents released by teachers include the preview before class, the consolidation content after class and the extended information resources and resource clues which are provided by the content of classroom teaching.

Students receive teachers to publish content, to WeChat for media independent and participatory learning resources related information, when students become the subject of study, teachers as a guide, supporters of the role. By WeChat, the students in the learning process, found problems in a timely manner to provide teachers with feedback information (synchronous or asynchronous) interaction and exchange of teachers, can of course to other students seeking help to complete their learning needs.

Individual teachers can guide the students can also participate in the group learning to provide students with help, in this process, the teacher should evaluate the students according to the actual situation of the students, but also to organize evaluation behavior between the students themselves and students, discover their problems in the study and give a reminder or modify opinions. After WeChat learning, learning behavior once again return to the classroom, in solving the previous stage of the remaining problems, into the next stage of learning.

\section{HYBRID LEARNING PlATFORM INTERACTIVE MECHANISM BASED ON WECHAT}

In order to achieve good results of learning, students need to fully participate in the study practice. Therefore, we need to focus on the interaction process and form in the activities, both in the classroom environment and WeChat environment, but also interact with students in the WeChat environment. This paper focuses on the combination of the interactive behavior of functions and features of design under the environment of WeChat.

\section{A. Interactions Between WeChat Platform and Classroom Environment}

In the classroom environment, the interaction between teachers and students is a kind of face-to-face communication among teachers and students, which is the same as the traditional classroom teaching. In this process, the interaction is launched by teachers and students to participate in. WeChat learning is done after class. Teachers set the appropriate difficulty learning tasks to students and students complete their tasks in the WeChat environment. Students share their results, evaluate each other's achievements, and then improve their results according to the evaluation results. Teachers will put the typical achievement in the classroom with the students to discuss. The interactions between WeChat platform and classroom environment is shown in Figure 2.

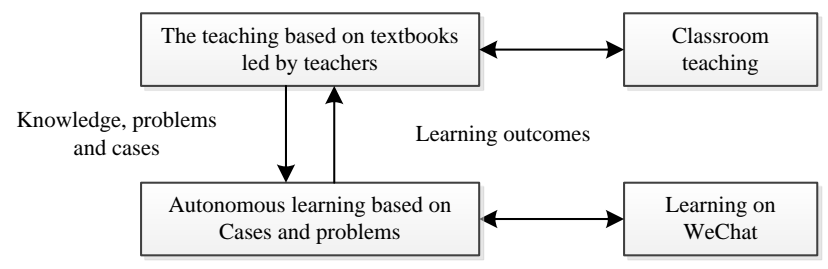

Fig. 2. Interactions between WeChat platform and classroom environment

\section{B. Interactions of Autonomous Learning on WeChat platform}

In the WeChat environment of autonomous learning, learning by teachers according to the given target, subject knowledge and information resources etc. launched interactive behavior, students according to their own needs to seek the help of teachers or other students, teachers or other students to support such interactions can occur in private chat, friends and group environment.

\section{Interactions of Participatory Learning on WeChat Platform}

In participatory learning, students participate in learning independently or by group. Teachers interact with students or other teachers synchronously or asynchronously, which is to accomplish the task of learning. There are interactions among students, teachers and students of the group. There are discussions, cooperation, evaluations and other interactions among the groups. In this process, students are the main body and teachers only play the role of guiding and help.

\section{Mobile Micro Course Construction BASED ON WECHAT PLATFORM}

\section{A. Selection platform}

Considering the time and cost, it is a better way to use the existing online WeChat teaching platform. On the platform side, teachers can create their own micro mobile course according to their needs. In the mobile terminal, the number of public concern students through the WeChat platform to enter the curriculum.

\section{B. Creating course}

Mainly include according to the course content and object oriented writing script, collecting materials, making and uploading course. It should be noted that the course here are generalized course, both traditional classroom teaching class and non classroom teaching class, such as competition counseling, etc.. The main purpose is to make full use of WeChat's convenient mobile carrier for some aspects of learning, to enhance learning interest and effectiveness. 


\section{Releasing course}

the curriculum content upload platform, according to the teaching plan regularly published, may also need to upload and publish some temporary teaching materials, curriculum resources will be released by WeChat real-time platform pushed to students.

\section{Feedback and Analysis}

After the release of curriculum resources, teachers interact with students in the background, and provide guidance for them. At the same time, the platform provides the function of data analysis, can the teaching resources of a curriculum evaluation, such as forwarding share number reflects the popularity of this course, the teachers according to the analysis results to adjust and improve teaching content of the follow-up arrangements.

\section{SUMMARY}

So far, the role of WeChat and other online communication tools has exceeded the original function. WeChat platform is more and more common in micro mobile course teaching. In this paper, the teaching theory of micro mobile course is introduced and based on which, we believe that the micro mobile course teaching based on WeChat platform conforms to the teaching theory. It is the promotion of new technology development to the teaching concept and teaching form. The teaching design principles of micro mobile course are discussed. The teaching design patterns of micro mobile course are analyzed. The learning interaction mechanism in micro mobile teaching is discussed. Finally, combined with the actual teaching situation, the construction method of micro mobile courses based on WeChat platform is put forward, which provides support for the research of new teaching mode.

\section{ACKNOWLEDGMENT}

This research was financially supported by the education and teaching project of College of Command Information Systems ZY2016007.

\section{REFERENCES}

[1] G. Siemens, "Connectivism: A Learning Theory for the Digital Age," Instructional technology \& distance learning, 2005. 2(1), pp.3-10.

[2] A. Dillard, "Mobile instructional design principle for adult learners," Oregon: University of Oregon, 2012, pp.28-43.

[3] T. Elias, "Universal Instructional Design Principles for Mobile Learning," The International Review of Research in Open and Distance Learning, 2011, pp.143-156.

[4] H. Tsai, S. S. C. Young, C. H. Liang, "Exploring the Course Development Model for the Mobi le Learning Context: A Preliminary Study," Proceedings of the Fifth IEEE International Conference on Advanced Learning Technologies, ICALT 2005, pp.437-439.

[5] X. Zhan, H.J. Chang, Q. Chen, "The Practice and Thoughts of Micromobile Learning of Open Education-Based on Haining TVU Branch. Journal of Anhui Radio \& Tv University, 2015.

[6] G Sun, T Cui, S Chen, W Guo, J. Shen, "MLaaS: A Cloud System for Mobile Micro Learning in MOOC," IEEE International Conference on Mobile Services, 2015, pp.120-127.

[7] J. W. Ma, "A Design and Teaching Practice of Micro Mobile Learning Assisting College English Teaching Mode base on WeChat Public Platform,".

[8] Y.S. Song, "Design and Implementation of Mobile Learning Platform in Higher Vocational Colleges Based on We Chat and Micro-site," Computer Knowledge \& Technology, 2016. 